\title{
INSTRUMENTS AND METHODS \\ AN EFFECTIVE PRESSURE ROOM SEAL IN ICE
}

\author{
By G. E. H. Ballard and R. O. Ramseier
}

(U.S. Army Cold Regions Research and Engineering Laboratory, Hanover, New Hampshire, U.S.A.)

\begin{abstract}
Several methods were tried to seal a room in ice which could be pressurized to the overburden pressure of the ice. We found that a keyed bulkhead consisting of two ice walls with an in-place frozen mixture of water, clay and styrofoam pellets between them produced an effective seal.

RÉsumé. Chambre sous pression étanche dans la glace. Plusieurs méthodes ont été essayées pour rendre étanche une cavité sous pression dans la glace. Nous avons trouvé qu'une cloison étanche renfermée composée de deux murs de glace entre lesquels géle après quelques heures un mélange d'eau, d'argile et de billes de "styrofoam". Sous une pression de $2,1 \mathrm{~kg} \mathrm{~cm}^{-2}$, la cavité resta bien étanche.

Zusammenfassung. Wirksame Abdichtung von Eis-Hohlräumen. Zur Abdichtung von Hohlräumen in Eis, die dem Druck des darüberliegenden Eises ausgesetzt sind, wurden verschiedene Methoden erprobt. Eine eingekeilte Schotte, bestehend aus zwei Eiswänden, deren Zwischenraum mit einer Gefriermischung von Wasser, Ton und "Styrofoam"-Kügelchen gefüllt wurde, erwies sich bei einem Druck von $2,1 \mathrm{~kg} \mathrm{~cm}^{-2}$ als wirksame Dichtung.
\end{abstract}

IN 1962 plans were made to pressurize a small chamber in the Camp Tuto ice tunnel located in the Greenland Ice Sheet near Thule. It is the purpose of this note to describe how the chamber was eventually sealed for pressurizing. The results obtained from the pressurized room will be published at a later date.

Initially a steel bulkhead capable of withstanding pressures of $2 \cdot 1 \mathrm{~kg} . \mathrm{cm} .^{-2}$ was built. As shown in Fig. I, this steel bulkhead was mounted at the entrance of the chamber with foam rubber placed between the carefully planed ice wall and the bulkhead. It was thought that, as the room was pressurized, the bulkhead would squeeze the foam rubber making an air-tight seal. Unfortunately, when put to the test, the room was accidently pressurized

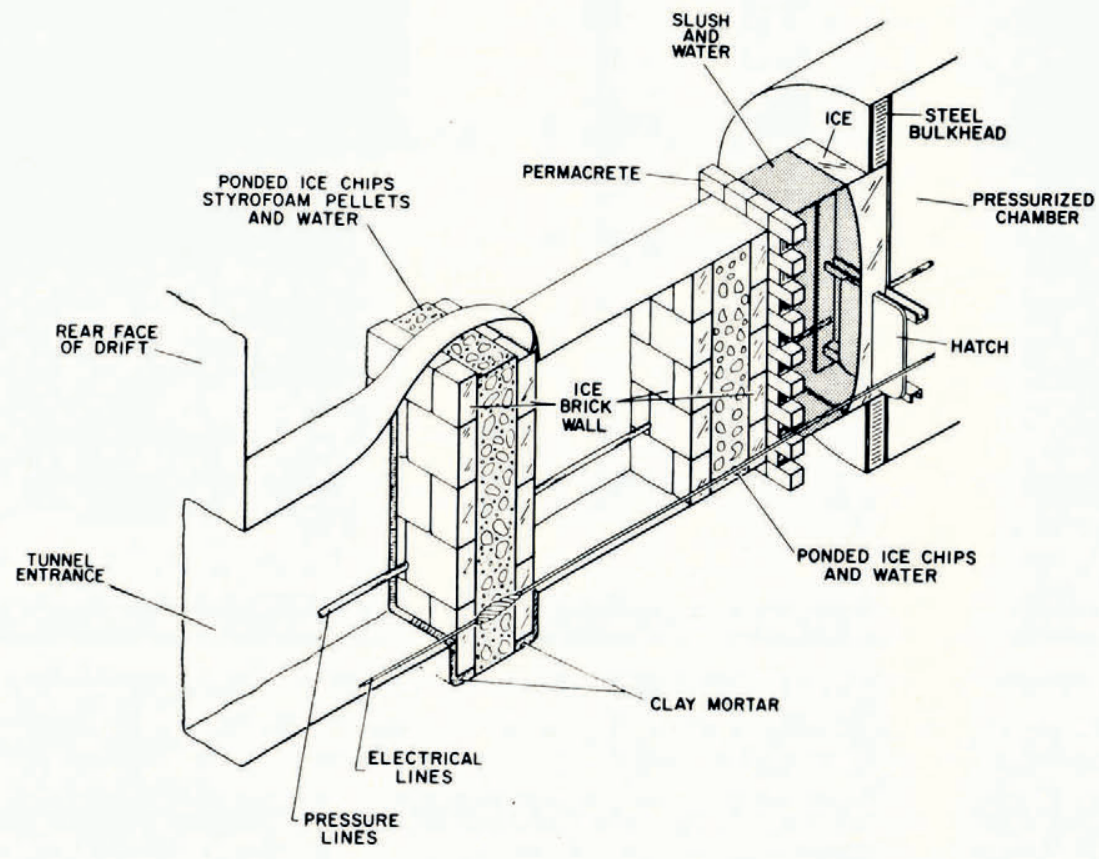

Fig. I. The successful seal is shown at the left side of the figure and the remnants of the unsuccessful seals are shown to the right 
beyond the limits of the bulkhead, breaking its window and warping the steel structure, which resulted in many air leaks.

To avoid prefabrication of another bulkhead at a geographically distant point and at great expense, it became essential to find a sealing method using locally available natural materials.

Our first attempt involved the freezing of slush and water around the existing bulkhead. Under normal conditions, the mean temperature of the ice tunnel and pressure chamber entrance is $-10^{\circ} \mathrm{C}$. However, during the summer, when the work was being carried out, traffic of vehicles and people increased the air temperature to $-8^{\circ}$ to $-6^{\circ} \mathrm{C}$. The heat generated by one man working at the face of the bulkhead raised the air temperature to near and sometimes above $o^{\circ} \mathrm{C}$. Thus the task of building up a thick ice layer around and over the bulkhead was tedious and time-consuming. On completion the chamber was partially pressurized, but leaks had developed all around the perimeter of the bulkhead by the time a pressure of $0.15 \mathrm{~kg}$. $\mathrm{cm} .^{-2}$ was reached.

Our next attempt involved building a wall in front of the steel bulkhead using bricks of permacrete, an artificial building material made by freezing water-saturated granular material. The permacrete bricks were first cast from fine silt and water and then mortared with unfrozen silt and water. The $50 \mathrm{~cm}$. space between the permacrete bricks and the bulkhead was filled with a mixture of slush and water. After the slush had frozen, the chamber was pressurized to $0.4 \mathrm{~kg}$. $\mathrm{cm}^{-2}$. Leaks developed at and near the top of the permacrete wall. This was not too surprising as it was quite difficult to effect a seal with slush and water at the tunnel roof. The close of the field season prevented further experimentation. The average annual closure in this part of the tunnel is about $15 \mathrm{~cm}$. per year both vertically and horizontally, and it was thought that this natural closure would produce an effective seal around the permacrete plug.

The following spring (1964) the room was again pressurized and it was found that the natural closure of the ice had not effected a seal, if anything the leaks were worse. Only a pressure of $0.15 \mathrm{~kg} . \mathrm{cm}^{-2}$ was possible with the same compressor unit before leaks developed on the sides of the seal. It was obvious that a new concept was required using materials that were "locally" available but would deform more readily as the tunnel closed.

A seal primarily made of ice, being of the same material as the tunnel walls, should have deformational characteristics similar to the walls. The placement of an ice plug as a seal in a tunnel, however, raises several technical problems. At some stage in the construction water must be frozen in place. It was desirable to use the lower temperature of the surrounding ice to absorb the latent heat of fusion of the freezing water. As noted previously this drastically restricts either the amount of water used or the rate of construction in this particular tunnel. The volume expansion during freezing and the volume shrinkage as the ice plug temperature approaches equilibrium with the temperature of the tunnel walls are problems also, unless the shrinkage rate is less than the natural closure rate. Furthermore, the water must be held in place during freezing to prevent air space at the intersection with the tunnel roof. It was decided that small amounts of a foreign material could be introduced as a mortar between a previously frozen block of ice and the tunnel walls. Sodium montmorillonite and water appeared feasible as a mortar. This clay is readily available in Greenland and can be purchased commercially. *

The sodium montmorillonite-water mixture has some very desirable features as a mortar for ice. The water in the mortar is structurally held to the clay surface. Thus, when the mortar freezes in contact with ice, a continuous structural bond would be expected. This mortar has a workable consistency over a very large range of water content, and the temperature at which the mortar will freeze varies with the water content.

\footnotetext{
* "Aquagel", registered trade-mark of Baroid Division of National Lead Co. for Wyoming bentonite which is a sodium montmorillonite.
} 


\section{Method Appraisal}

Crude experimentation on the job indicated that a mortar consisting of roughly one part by volume of clay to three parts of water remained plastic to $-5^{\circ} \mathrm{C}$. and was very tough and strong at the ambient temperature of the tunnel $\left(-\mathrm{IO}^{\circ} \mathrm{C}\right.$.). Ice bricks $\mathrm{I} 5 \mathrm{~cm}$. thick and $30 \mathrm{~cm}$. square were cut from the walls of the main tunnel by means of a chain saw equipped with ice-cutting teeth. Two walls $15 \mathrm{~cm}$. thick and $30 \mathrm{~cm}$. apart were raised in stages of $30 \mathrm{~cm}$. Chipped ice and water were ponded between the walls and allowed to freeze prior to the construction of the next stage.

The third stage split open during freezing of the ponded ice and water. When the plug was completed the effectiveness was tested by raising the pressure in the pressure chamber. Gas escaped from several positions at the contact of the mortar and the tunnel wall. Several attempts to patch these leaks proved unsuccessful. Although the mortar had remained plastic during the construction and was very firm at the ambient temperature of the tunnel it had not maintained a seal during the contraction of the plug under the declining temperature. However, enough experience was gained that an effective seal seemed probable.

\section{Construction of an Effective Seal}

Figure I shows the details of the successful second attempt at sealing the chamber with ice bricks and montmorillonite mortar. A key-joint was utilized to assure contact during thermal shrinking and styrofoam (expanded polystyrene) pellets were introduced to prevent splitting during the phase-change expansion. A key $20 \mathrm{~cm}$. deep and $60 \mathrm{~cm}$. wide was cut into the tunnel walls and floor. The roof in the vicinity of the key was raised nearly $60 \mathrm{~cm}$. to allow the water and ice chips to be ponded well above the normal tunnel roof. This key served a twofold purpose. First, it allowed a mortar joint to be made parallel with the tunnel crosssection; as the ice plug contracted under decreasing temperature, the slip joint would not be subjected to a tension failure. Second, by raising the key above the original tunnel, the central portion of ice chips and water could be poured continuously well above the tunnel roof.

The mortar mix was considered satisfactory and was again mixed with three parts water to one part clay by volume. The inside wall was raised by first using $2.5 \mathrm{~cm}$. of mortar in the slip joint and then just enough mortar to assure contact between the ice bricks. The outside wall was raised, as shown in Figure I, above the original tunnel roof. An opening approximately $15 \mathrm{~cm}$. high and $30 \mathrm{~cm}$. wide was left to allow the ice and water to be poured in. Crushed ice and ice chips were mixed with styrofoam pellets in a ratio of 4 to $\mathrm{I}$. The ice and styrofoam mixture was poured in a dry condition between the walls and just enough water was added to prevent the styrofoam and ice from separating. To avoid a large hydrostatic head on the plastic mortar joints, the center of the plug was poured in stages. However, care was taken to pour each successive stage before the previous stage was more than half frozen. Freezing started at the ice brick walls and the tunnel walls thus protecting the mortar from undue pressure. After the ponded ice chips were poured and frozen, the pressure was raised slightly in the chamber, to hold the plug snugly against the outside edge of the key during cooling of the ice plug. As the temperature of the ice plug neared that of the tunnel, $0 \cdot 7$ $\mathrm{kg}$. $\mathrm{cm} .^{-2}$ was introduced to the pressure chamber. One month later the pressure chamber was raised to $2 \cdot \mathrm{I} \mathrm{kg} . \mathrm{cm}^{-2}$, the estimated overburden pressure of the ice at this location.

No splitting or fractures were noted in the ice walls or in the central poured plug; the styrofoam pellets crushed to provide the needed volume during freezing. The mortar remained noticeably plastic to $-5^{\circ} \mathrm{C}$. and no leaks could be detected around the key. The chamber was effectively sealed.

\section{MS. received 31 December 1964

